\title{
Expansão do crédito no Brasil e a vulnerabilidade do consumidor
}

\author{
Adriana Sbicca* \\ Vinícius Floriani ${ }^{* *}$ \\ Yohanna Juk $k^{* * *}$
}

Resumo: Através da análise de informações recentes quanto à intensa expansão do crédito à pessoa física, inadimplência e comprometimento de renda no Brasil, este texto identifica a população de baixa renda como consumidores vulneráveis. Uma discussão nascente destaca como características principais da vulnerabilidade do consumidor a pouca experiência com a contratação do crédito e uma tendência à fragilização de sua condição financeira devido às dívidas adquiridas e à capacidade de saldá-las. $\mathrm{O}$ texto chama a atenção para que, além da disponibilidade de informação para que os consumidores possam decidir pela contratação ou não de dívida, as tendências futuras da situação financeira dessas famílias devem ser analisadas, o que envolve expectativa de renda e a identificação de padrões de comportamento que influenciam a contratação do crédito.

Palavras-chave: Vulnerabilidade do consumidor; Crédito.

Classificação JEL: D03; D12.

\footnotetext{
"Doutora em Economia de Empresas pela Escola de Economia de São Paulo - Fundação Getúlio Vargas (FGV). Professora do Departamento de Economia da Universidade Federal do Paraná. Endereço eletrônico: adsbicca@ufpr.br

${ }^{* *}$ Graduando em Ciências Econômicas da Universidade Federal do Paraná (UFPR). Endereço Eletrônico: floriani. vinicius@gmail.com

*** Graduanda em Ciências Econômicas da Universidade Federal do Paraná (UFPR). Endereço Eletrônico: yohannajuk91@ gmail.com
} 


\section{Introdução}

A expansão do crédito no Brasil se deu de forma excepcionalmente rápida nos últimos 10 anos. De maneira concomitante ao aumento expressivo na demanda por crédito tem ocorrido o endividamento das classes de renda mais modestas, com crescimento significativo da participação do cartão de crédito, modalidade que apresenta o maior indicador de inadimplência. Essa constatação estimulou o debate acerca das consequências do aumento do crédito ao consumidor e as implicações para a economia brasileira. A discussão a respeito da acentuada expansão da disponibilidade de crédito, do crescimento do endividamento das famílias brasileiras e da inadimplência, tem estado presente em jornais de grande circulação nacional. Este debate ganha importância quando relacionado a uma literatura econômica recente que trata da vulnerabilidade do consumidor, tema já levado em consideração pela legislação como atesta o Código de Defesa do Consumidor (Lei $n^{\circ} 8.078$ de 11 de setembro de 1990). Na teoria econômica a vulnerabilidade do consumidor pode ser relacionada à assimetria de informação e sob esse ponto de vista podemos identificar a preocupação do legislador em garantir a disponibilidade das informações importantes para a decisão do consumidor. A análise das informações quanto a crédito no Brasil, inadimplência e comprometimento de renda, identifica a população de baixa renda como vulnerável e chama a atenção para que, além da disponibilidade de informação para que os consumidores possam decidir pela contratação ou não de dívida, as tendências futuras da situação financeira dessas famílias devem ser analisadas, o que envolve expectativa de renda e a identificação de padrões de comportamento que influenciam a contratação do crédito.

A partir de indicadores da atual condição financeira das famílias brasileiras frente ao crescimento do crédito, este artigo objetiva analisar a vulnerabilidade do consumidor no país. O trabalho está dividido em 4 seções, além desta introdução. A seção 2 apresenta mais detalhes sobre o recente crescimento do crédito no Brasil. As consequências observadas para as finanças do consumidor são tratadas na seção 3. A seção 4 trata do adimplemento das diversas faixas de renda e enfatiza a inclusão da classe de renda mais baixa no mercado de cartão de crédito como evento importante para se refletir sobre vulnerabilidade do consumidor brasileiro. Por fim são apresentadas as considerações finais.

\section{Trajetória recente do mercado de crédito no Brasil}

Nos últimos anos, as operações de crédito apresentaram acentuado crescimento em seu volume. A série histórica produzida pelo Banco Central aponta que, enquanto de 1995 a março de 2003 o aumento foi de apenas 1,6\%, os últimos 9 anos apresentaram crescimento real do crédito na ordem dos 209,9\%. $\mathrm{O}$ saldo de empréstimos concedidos cresceu em 2012, sobretudo n a modalidade de pessoa física, representou o maior componente do crédito no país, com $30 \%$ do total como mostrado no gráfico 1.

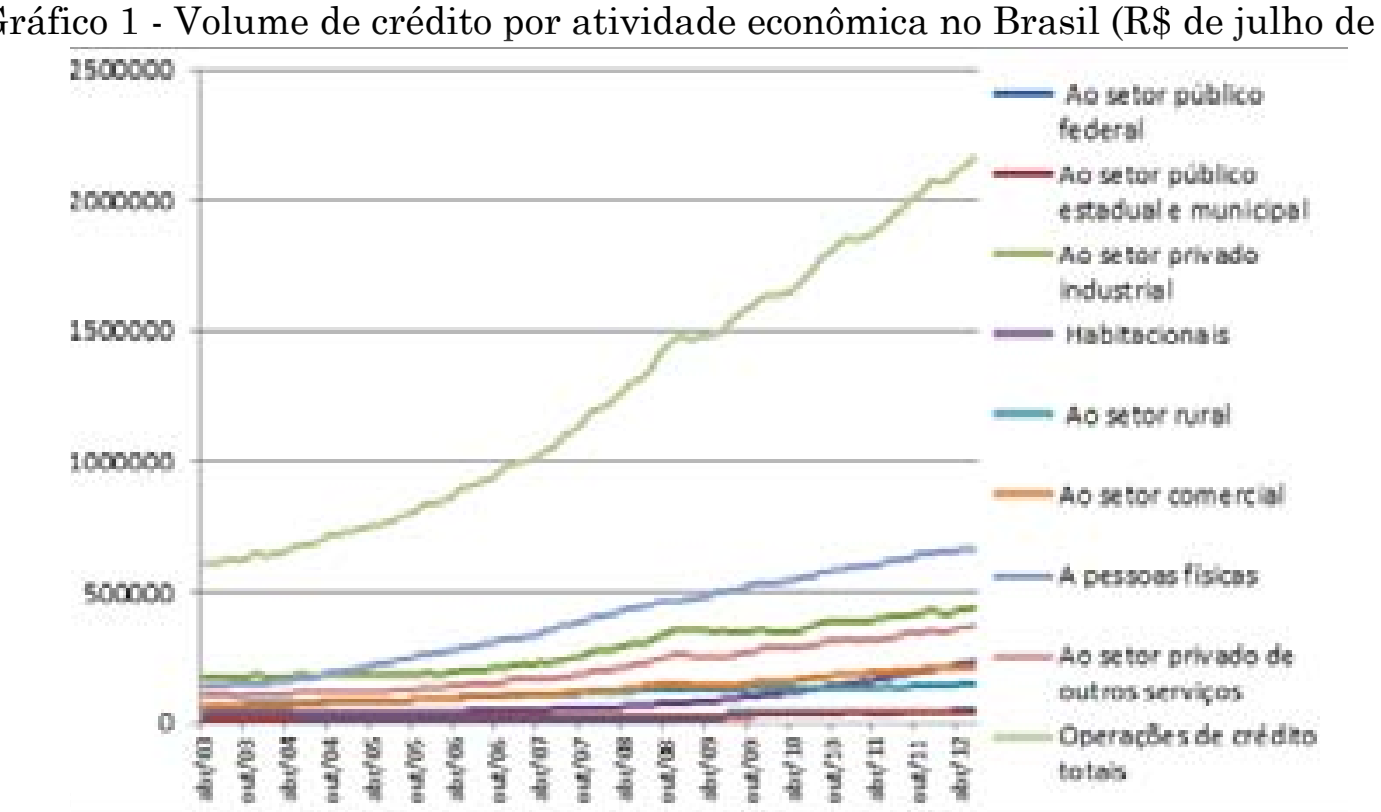

Fonte: elaborado pelos autores com base nos dados do Banco Central e IBGE

Em maio deste ano, a relação crédito/PIB, mensurada pelo Banco Central, atingiu pela primeira vez na história brasileira o patamar de 50,1\%. A quantidade de crédito, por si só, não sugere problema, mesmo porque a proporção crédito/PIB brasileira é inferior às taxas encontradas em economias mais maduras e até mesmo em economias de outros países em desenvolvimento, como China e África do Sul (Banco Mundial, 2012), como visto no gráfico 2.

Gráfico 2 - Crédito Doméstico para o setor privado (\% do PIB) - 2011 250

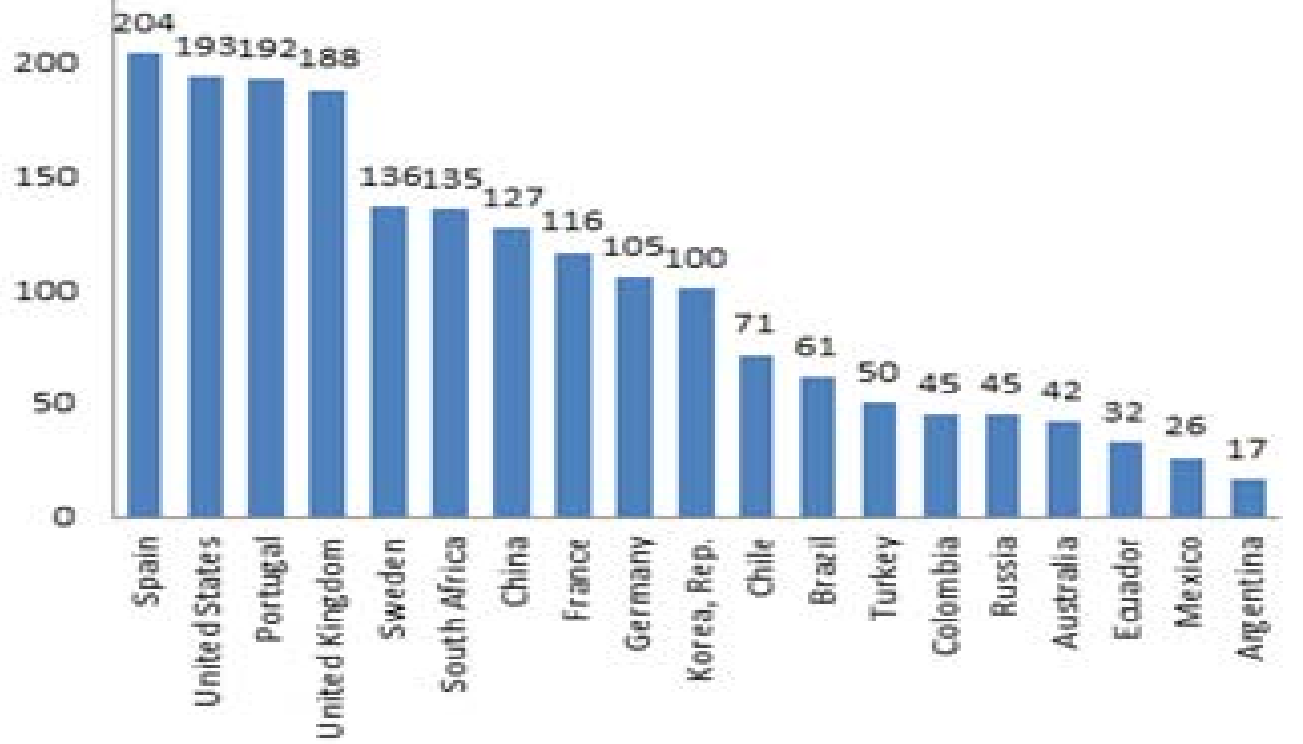

Fonte: elaborado pelos autores com base nos dados do Banco Mundial 
A velocidade com que a expansão do crédito se deu no Brasil nos últimos anos, entretanto, provoca indagações quanto às possíveis consequências econômicas, o que convida a um olhar mais detalhado para o fenômeno no Brasil. A demanda por crédito pelo consumidor apresentou elevação, tendo crescido $38,97 \%$ de janeiro de 2007 a maio de 2012 segundo dados do Serasa Experian. O crescimento relativo à faixa de renda inferior, de até $R \$ 500,00$ individuais mensais, foi de $112,72 \%$. A partir do início de 2010 a demanda de crédito por esta faixa de renda tornou-se mais elevada que as demais, e apresentou taxa de crescimento superior à média.

Ao analisarmos o Índice de Qualidade de Crédito, elaborado pelo Serasa Experian com base no perfil socioeconômico do indivíduo e na consequente probabilidade de incorrer em inadimplência, notamos uma leve queda global de $1,36 \%$ entre 2007 e 2012, que não representa alteração relevante na qualidade de crédito durante o período. Essa estabilidade também pode ser observada nos dados do Banco Central (gráfico 3), que apresentam o risco do crédito concedido em relação ao tempo de atraso do tomador de empréstimo, mensurado de AA (sem atraso) a H (atraso superior a 180 dias).

Gráfico 3 - Risco do crédito concedido ao consumidor

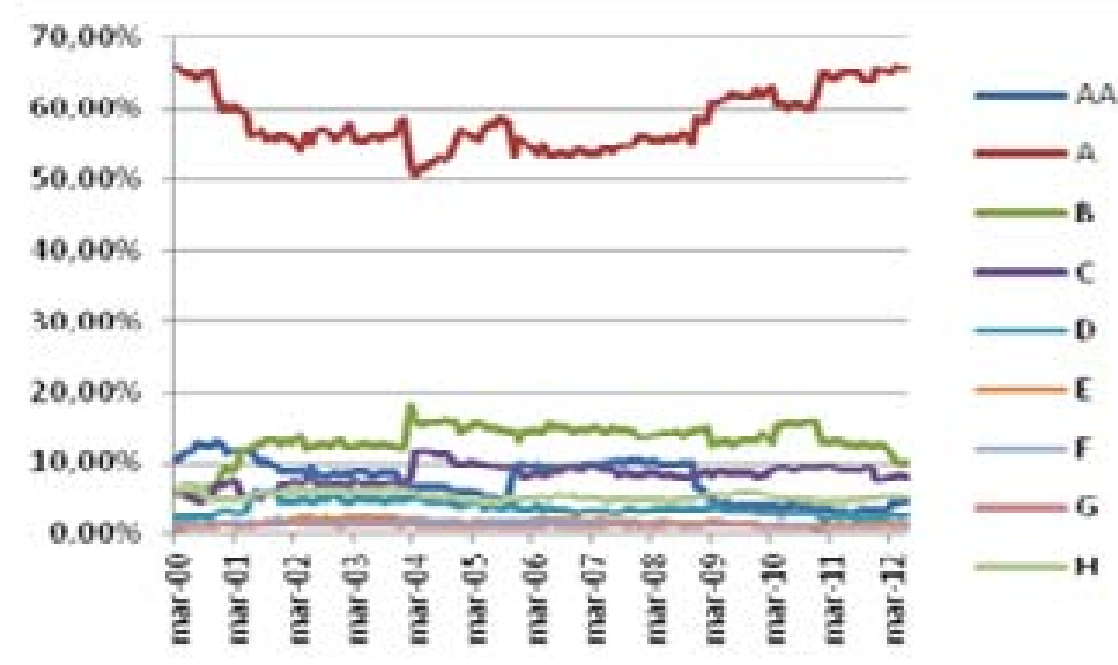

Fonte: elaborado pelos autores com base em dados do Banco Central

Em paralelo ao expressivo crescimento do crédito à pessoa física, apresentado anteriormente, os dois indicadores de qualidade mencionados não apontam uma elevação expressiva no risco. $O$ número de empréstimos concedidos à pessoa física com até 60 dias de atraso (categorias AA, A, B e C somadas) representou, em junho de $2012,88,2 \%$ do montante total, contra $87,9 \%$ no início da série, em março de 2000 .

\section{Endividamento e comprometimento de renda}

A proporção da dívida total das famílias em relação a sua renda anual passou do patamar de 18,39\% em 2005, a 43,27\% em abril de 2012 (BACEN, 2012). Este percentual, porém, é menor do que o observado em países desenvolvidos como, por exemplo, a Suécia, Suíça ou Reino Unido, com endividamento acima de $100 \%$ ou Alemanha, próxima de $80 \%$ (Ahearne \& Wolff, 2012).

O comprometimento da renda familiar com dívidas em relação ao rendimento mensal apresentou um crescimento menos intenso, partindo de $15,52 \%$ em 1995 a $22,1 \%$ em abril de 2012 (BACEN, 2012). O prolongamento dos prazos para financiamento somado ao constante aumento na renda real média dos últimos anos amenizam estes percentuais e remete à questão quanto ao comportamento futuro da renda dos brasileiros para a manutenção do comprometimento da renda em níveis adequados. A elevação no volume de dívidas já contraídas, e que pelo mesmo em parte resta pagar, poderia levar a um crescimento acentuado do comprometimento da renda presente e futura caso a renda tenha seu ritmo de crescimento frustrado. Detalhando o tipo de dívida que o brasileiro tem adquirido, percebe-se diferença com relação a países mais desenvolvidos. A composição do crédito de pessoa física nos países ricos com altos níveis de endividamento das famílias tende a ter grande parcela de dívida imobiliária (Ahearne \& Wolff, 2012), o que não acontece hoje no Brasil. Em junho de 2012, 60,54\% do crédito à pessoa física foi adquirido através de cartões de crédito e cheque especial, sendo que o cheque especial figura como principal modalidade desde o começo da série, como observado no gráfico 4 (BACEN, 2012).

Gráfico 4 - Composição de Crédito de Pessoa Física

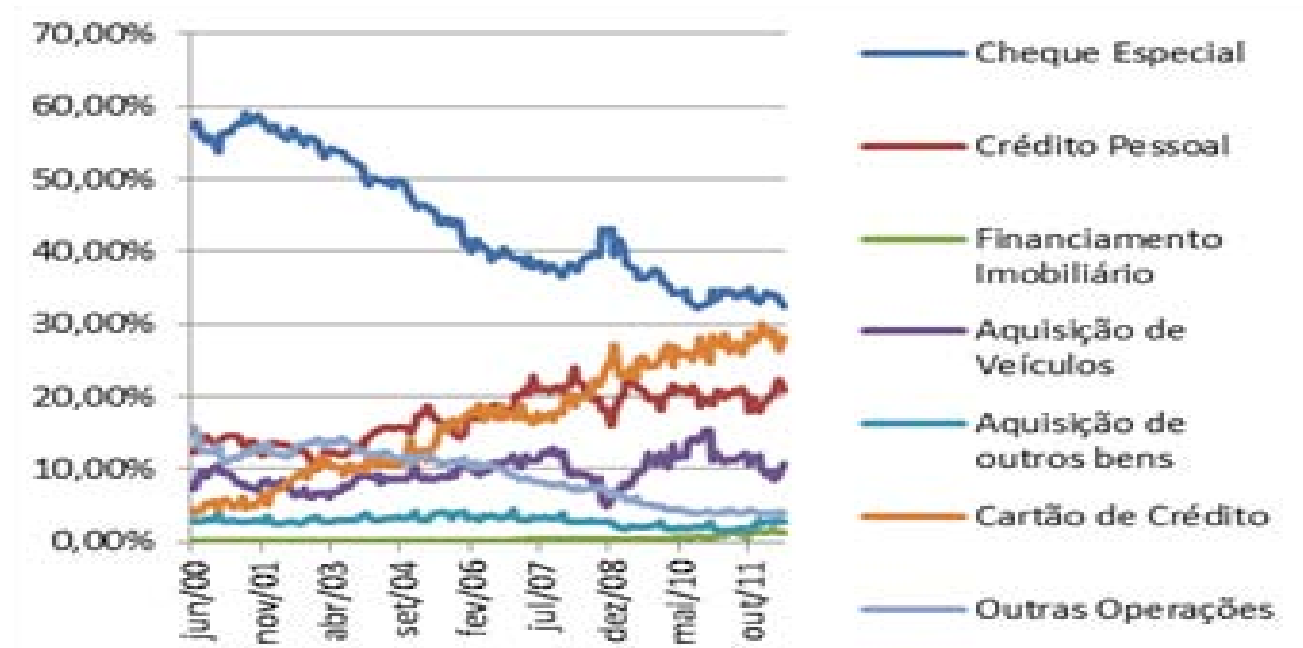

Fonte: elaborado pelos autores com base em dados do Banco Central 
O financiamento imobiliário iniciou a série com $0,05 \%$ e representa apenas $1,28 \%$ ao final dos 12 anos compreendidos. Pode-se observar, também, uma possível substituição da utilização de cheque especial por cartões de crédito, em coerência com o histórico do aumento da inserção deste meio de pagamento no país.

O crédito direcionado, representando $35,8 \%$ do crédito total à pessoa física, teve alterações de composição mais expressivas, com a modalidade Habitacional passando de $15 \%$ a $25 \%$ de 2006 a 2011. Os componentes BNDES Direto, BNDES Repasse e Habitacional representaram, no último ano, $83 \%$ do crédito direcionado. Assim, em termos agregados, a utilização do crédito por pessoa física no Brasil para financiamento imobiliário passou de aproximadamente $5 \%$ em 2006 para algo próximo de 10\% em 2011, mas representa pouco do crédito utilizado pelos brasileiros no período se comparado, por exemplo, ao cartão de crédito.

É interessante notar como as análises se alteram quando são usados indicadores que levam em consideração detalhes da situação de inadimplência atual. A proporção de empréstimos com pagamento de juros ou amortização do principal com atraso superior a 90 dias sobre o montante total apresenta estabilidade, com satisfatórios 3,6\% em 2011 e uma média de 3,7\% nos últimos cinco anos. A mesma razão para o crédito ao consumidor, entretanto, deteriorouse dos 5,7\% em 2010 para 8\% em maio de 2012 (Perez-Gorozpe \& Bala, 2012).

Gráfico 5 - Pagamentos em atraso (\%) há mais de 90 dias

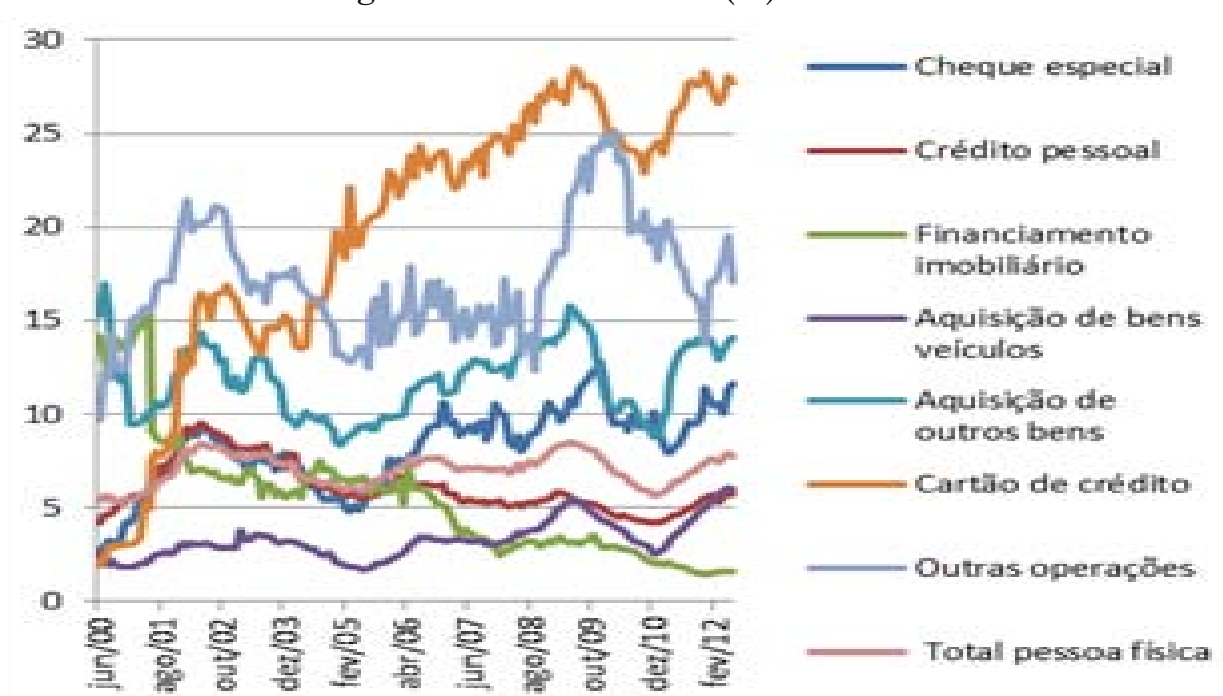

Fonte: elaborado pelos autores com base em dados do Banco Central

O gráfico 5 apresenta o percentual de pagamentos em atraso há mais de 90 dias, segundo o Banco Central. Nota-se que a modalidade com maior aumento relativo na participação da concessão de crédito à pessoa física, o cartão de crédito, apresenta também maior crescimento e maior percentual absoluto de pagamentos com pelo menos 3 meses de atraso.

Dentre os diferentes meios de pagamento utilizados pelos consumidores que geraram inadimplência, o cartão de crédito merece destaque. De acordo com a Pesquisa Nacional de Endividamento e Inadimplência do Consumidor, PEIC, (CNC, 2012), 74,8\% dos consumidores afirmaram possuir dívida com cartão de crédito em junho de 2012, com ligeiro crescimento desde o mesmo período do ano passado. Esta pesquisa aponta que o grupo com renda inferior a dez salários mínimos apresentou maior percentual de contas em atraso (24,5\%). O número de famílias endividadas foi de $58,2 \%$. O total de famílias que declararam não ter condições de pagar suas dívidas no futuro foi 8,1\%, o tempo médio de atraso foi de 59,8 dias e a parcela da renda comprometida foi $28,7 \%$, em média. $\mathrm{O}$ tempo de comprometimento com dívidas foi de 6,3 meses no grupo de menor renda, contra 6,9 meses no grupo de maior renda, acima de dez salários mínimos. Como o cartão de crédito se destaca quando observamos a inadimplência do consumidor, na próxima seção trataremos com mais detalhes sobre o crescimento recente do uso deste meio de pagamento.

\section{$4 \mathrm{O}$ uso do cartão de crédito pelas diversas faixas de renda}

O número de cartões de crédito aumentou $13 \%$ entre 2011 e 2012 havendo hoje em torno de 0,9 cartão de crédito para cada brasileiro (ABECS, 2012). Já o número de transações cresceu $17 \%$ entre os primeiros trimestres de 2011 e 2012 , atingindo 885 milhões de transações nos primeiros três meses de 2012. Uma em cada quatro solicitações de cartão de crédito provem do segmento "Periferia Jovem", caracterizado por jovens trabalhadores de baixa renda com pouca qualificação e por estudantes de periferia e famílias que recebem assistência do Estado. E essas solicitações cresceram nos últimos anos, de 21,75\% em 2009 para 25,54\% em 2011 (Serasa Experian, 2012).

A situação dos consumidores brasileiros diante do aumento do crédito despertou a atenção do Fundo Monetário Internacional (García-Escribano, 2012). Em relatório de julho de 2012 sobre a conjuntura econômica brasileira, foi destinada uma seção ao "crescimento do crédito ao consumidor e o risco de estresse financeiro das famílias". Com base na Pesquisa de Orçamentos Familiares, este relatório compara a penetração de diferentes modalidades de empréstimo nos diversos níveis de renda do brasileiro entre 2003 e 2009, sendo levados em consideração: crédito imobiliário, cartão de crédito, cheque especial, empréstimos e parcelamento de bens duráveis. Ao passo em que o percentual de usuários de cartão de crédito elevou-se de 59,9\% para 64,4\% na faixa de renda mais elevada ( $5 \%$ finais da distribuição nacional), todas as faixas até a metade da distribuição tiveram crescimento próximo de, ou superior a, $100 \%$ em percentual de usuários. O cartão de crédito foi a modalidade com maior crescimento no período, atingindo $26,8 \%$ de penetração média no Brasil. Estes dados apontam um mercado claramente concentrado nas classes superiores de renda, já que apenas $10,6 \%$ dentre os $25 \%$ mais pobres da população possuíam cartão de crédito em 2009 enquanto $59,9 \%$ entre os $5 \%$ mais ricos utilizavam. esta forma de pagamento. Entretanto, o crescimento do número de usuários foi bastante intenso na população com rendimentos menores. 
Os bancos estão atentos às possibilidades de crescimento do segmento cartão de crédito nas faixas de renda mais baixas. Fernando Chacon, diretor de Marketing e Cartões do Itaú, divulgou em relatório de outubro de 2007 a delimitação do público alvo das empresas de cartão de crédito - população urbana, com idade superior a 18 anos e renda mensal mínima de $\mathrm{R} \$ 250$ (Chacon, 2007). Em dezembro de 2009, tal rendimento seria equivalente a $R \$ 294,48$, próximo dos $5 \%$ com menor renda no país à época e com penetração de cartões de crédito em torno de $5 \%$ desta população. A busca por público alvo não tradicional pelas empresas de cartão de crédito já foi notada também nos EUA, neste caso estudantes de graduação e a população de baixa renda (Salomon, 1998).

A inclusão de indivíduos com níveis de renda inferiores a um salário mínimo no público alvo de emissores de cartão de crédito no Brasil pode ser melhor compreendida quando tratamos de fonte de lucro para o segmento. O Banco Central, Ministério da Justiça \& Ministério da Fazenda (2010), em relatório de maio de 2010 sobre a indústria de cartões de pagamento, identificam que "o lucro do lado dos emissores apresentou dependência das receitas financeiras advindas de financiamento dos clientes. Com efeito, em muitos casos, a retirada dessa fonte de receita na análise os tornaria deficitários. Tal fato corrobora o entendimento do mercado de que o cartão de crédito para as instituições financeiras representa o uso de dois produtos, o de pagamento e o de facilitador da oferta de crédito." (idem, 2010, p. 8). Entre 2003 e 2007, as receitas com o crédito rotativo e multa devido à inadimplência cresceram em média $19,5 \%$ ao ano, com participação $60 \%$ maior em relação ao total no último ano citado. O Banco Central através da Circular 3.52/2012 e o Conselho Monetário Nacional (Resolução 3.99/2012) têm procurado regulamentar o funcionamento do produto cartão de crédito, sobretudo no que diz respeito à contratação de crédito rotativo e multas (Sbicca \& Fernandes, 2011). O resultado preliminar, entretanto, não foi o de queda na inadimplência superior a 90 dias, como demonstrado anteriormente.

Países como os Estados Unidos e a Austrália reconheceram características de vulnerabilidade dos consumidores diante do crédito e desenvolveram legislações para protegê-los. Em 2009, o Senado americano aprovou o Credit Card Act, que regula o fornecimento de crédito, restringindo a oferta para consumidores vulneráveis como famílias de baixa renda e jovens universitários.

Do ponto de vista jurídico, o Brasil também reconhece essa característica do consumidor e há meios legais de proteção elaborados e aplicados a partir do reconhecimento dessa fragilidade, como o Código de Defesa do Consumidor. $\mathrm{Na}$ literatura acadêmica, Brennan e Alexiades (2005) afirmam que consumidores que possuem menos capacidade de pagar suas dívidas, bem como menos conhecimento das consequências de longo prazo do endividamento são considerados consumidores vulneráveis. Essa vulnerabilidade parece crescente no caso do Brasil como os dados apresentados mostraram. As classes de renda inferior podem ser consideradas vulneráveis, visto seu comprometimento de renda e o crescimento da inadimplência com continuado aumento da demanda

por crédito. Ainda outros fatores comuns dessa camada da população podem ser acrescentados à reflexão sobre sua vulnerabilidade como a maior instabilidade da renda, menor experiência na contratação de crédito e demanda reprimida.

A expectativa de renda futura é uma variável que influencia o consumo e a contratação de crédito. Pensando neste aspecto, o Brasil apresentou uma expectativa de crescimento bastante positiva que foi acompanhada de aumento dos índices de confiança do consumidor. Vale destacar, entretanto, que a tendência de crescimento do PIB tem se reduzido e a faixa de mais baixa renda apresenta menor capacidade de enfrentamento imediato de eventuais crises que costumam ocasionar queda na renda das famílias. Além disso, classes de renda mais modesta apresentam maior endividamento líquido com menor possibilidade de liquidar bens para saldar dívidas.

Essa vulnerabilidade pode ser compreendida como uma característica do consumidor ou como uma situação que pode ser provisória. Neste sentido, este artigo chama a atenção para as circunstâncias que parecem ter induzido esta situação de vulnerabilidade: inexperiência na contratação de crédito, período com crescimento da renda e expectativa de continuidade no crescimento da capacidade de consumo. Isto não indica que a população de baixa renda seja inevitavelmente e sempre vulnerável, mas sim que essa faixa da população, no atual momento, apresenta tendências que podem levar a uma situação de estresse financeiro. A marcante desigualdade na distribuição de renda brasileira pode ser uma variável importante para se compreender mais profundamente a origem desta situação. Neste sentido, Baker et al. (2005) enfatizaram a distribuição de recursos na sociedade como elemento importante para se compreender o surgimento de situação de vulnerabilidade do consumidor.

Esse tema tem importância para se compreender as possíveis implicações econômicas da continuidade das tendências apresentadas pelos dados. A vulnerabilidade pode ser compreendida como um descompasso nas interações de mercado e pode ser levada em consideração no sentido de apontar uma nova tendência para a dinâmica econômica ou o esgotamento de uma tendência atual. No caso brasileiro, o grande mercado consumidor é uma variável importante para se tratar de crescimento econômico do país e a reflexão com relação ao potencial de crescimento futuro deste mercado envolve o tema vulnerabilidade do consumidor.

\section{Considerações finais}

Os dados apresentados ao longo do texto mostraram que o período recente de maior disponibilidade de crédito ao consumidor brasileiro não indica preocupação devido à relação crédito/PIB ou à qualidade do crédito. Uma observação mais detalhada sobre crédito e as diversas faixas de renda, no entanto, chama a atenção para a crescente piora dos dados com relação à população de menor renda, notadamente o aumento da inadimplência com o crédito rotativo do cartão de crédito. Essa análise reforça suspeita do Fundo Monetário Internacional que, ao analisar a situação econômica brasileira, 
salientou o possível estresse financeiro das famílias em saldar suas dívidas tendo em vista as elevadas taxas de juro ao consumidor.

Apesar da Legislação brasileira ter incorporado na Constituição Federal de 1988 atenção diferenciada aos consumidores e o Código de Defesa do Consumidor, tratar da "condição de vulnerabilidade" do consumidor, pouco se tem investigado o tema com objetivo de compreender as implicações econômicas decorrentes. Uma discussão nascente sobre vulnerabilidade do consumidor destaca como características principais a pouca experiência com a contratação do crédito e uma tendência à fragilização de sua condição financeira devido a dívidas adquiridas e a capacidade de saldá-las. Os dados observados para o Brasil quanto à contratação de crédito, comprometimento de renda e inadimplência chamam a atenção para a população de baixa renda e mostram como ela se enquadra no conceito de vulnerabilidade do consumidor. No caso brasileiro, a demanda historicamente reprimida e a possível instabilidade na renda dessas famílias na ocorrência de flutuações do PIB justificam o aprofundamento desta pesquisa e a reflexão quanto à necessidade de medidas para evitar o estresse financeiro da população de baixa renda.

\section{Referências}

ABECS. (2011). Associação Brasileira de empresas de cartões de crédito e serviços. URL (on line): <http://www.abecs.org.br/site2012/pesquisas.asp>. Acesso em: 06 de dez. de 2012.

Ahearne, A.; Wolff, G. B. (2012). The Debt Challenge in Europe. Bruegel and National University of Ireland. URL (on line): < http://www.bruegel.org/publications/

publication-detail/publication/686-the-debt-challenge-in-europe/>. Acesso em: 06 de dez. de 2012

BACEN (2011). Cartilha Cartão de Crédito. URL (on line): <http://www.bcb.gov.br/ pec/appron/apres/cartilha.pdf>. Acesso em: $06 \mathrm{de} \mathrm{dez.} \mathrm{de} 2012$.

BACEN, Ministério da Justiça \& Ministério da Fazenda, (2010). Relatório Sobre a Indústria de Cartões de Pagamentos. URL (on line): <http://www.bcb.gov.br/htms/ spb/Relatorio_Cartoes.pdf>. Acesso em: 06 de dez. de 2012.

BACEN (2012) URL (on line): <http://www.bcb.gov.br> Acesso em: 06 dez. de 2012.

Baker, S. M.; Gentry, J. W. \& Rittenburg, T. L. (2005) "Building Understanding of the Domain of Consumer Vulnerability". Journal of Macromarketing, v. 25, n. 2, p.128-139.

Banco Mundial (2012). URL (on line): <http://data.worldbank.org/indicator/FS.AST. PRVT.GD.ZS/countries/BR-GB-US?display=default)>. Acesso em: 27 de nov. de 2012.

Braunsberger, K.; Lucas, L.; Roach, D. (2004). "The effectiveness of credit-card regulation for vulnerable consumers". Journal of Services Marketing, 18(5), 358-370. doi:10.1108/08876040410548285
Brennan, L.; Alexiades, S. (2005). Vulnerable consumers and debt: can social marketing assist? 2nd Australasian Nonprofit and Social Marketing Conference, (Set.), p. 22-23.

Chacon, F. (2007). Baixa Renda: o cartão como instrumento de crédito. Indicadores do Mercado de Meios Eletrônicos de Pagamento. URL (on line): <http://ww28.itau. com.br/ImprensaNet/img/200710_cartao_instrumento_credito.pdf $>$. Acesso em: 06 de dez. de 2012.

CNC (2012). Pesquisa Nacional de Endividamento e Inadimplência do Consumidor. URL (on line): <http://www.cnc.org.br/central-do-conhecimento/pesquisas/ pesquisa-nacional-de-endividamento-e-inadimplencia-do-consumidor-8>. Acesso em: 06 de dez. de 2012.

GPO (2009). Credit card accountability responsibility and disclosure act of 2009. URL (on line): <http://www.gpo.gov/fdsys/pkg/PLAW-111publ24/html/PLAW111publ24.htm>. Acesso em: 06 de dez. de 2012.

García-Escribano, M., (2012) Consumer Credit Growth and Risks for Household Financial Stress. IMF Country Report, 12/192. URL (on line): <http://www.imf. org/external/pubs/ft/scr/2012/cr12192.pdf>. Acesso em: 06 de dez. de 2012.

Perez-Gorozpe, J; Bala, A. (2012). Credit Is Expanding Fast In Brazil, Colombia, And Peru, But Should The Banks Call It Quits?, Standard and Poors. URL (on line): $<$ http://www.standardandpoors.com/prot/ratings/articles/en/us/?articleType=H TML\&elq=42bc89a5e96645c0a1d48950df100db6\&assetID=1245336627724>. Acesso em: 27 de nov. de 2012

Salomon, A. (1998), Forward progress in Hispanic marketing, Credit Card Management, Vol. 10 No. 10 , pp. 56-8.

Sbicca, A.; Fernandes, A. L. (2011). Reflexões sobre o comportamento do consumidor e o cartão de crédito no Brasil, Revista Economia \& Tecnologia, 25, p. 171-178. 
